\title{
ATELIÊ ITINERANTE: RELATOS E EXPECTATIVAS DAS DISCIPLINAS EXTENSIONISTAS NA PANDEMIA ${ }^{1}$
}

\author{
ITINERANT STUDIO: REPORTS AND EXPECTATIONS FROM \\ EXTENSIONISTS DISCIPLINES DURING COVID 19 PANDEMIC ${ }^{\prime}$
}

\author{
Anelis Rolão Flores ${ }^{2}$, Juliana Lamana Guma ${ }^{3}$, Liese Basso Vieira ${ }^{4}$ e Marina de Alcântara ${ }^{5}$
}

\section{RESUMO}

A curricularização da extensão trouxe novos questionamentos e possibilidades ao ensino superior, fomentando a discussão sobre como essas práticas seriam inseridas teórica e metodologicamente no curso de graduação de Arquitetura e Urbanismo. Por meio dela percebemos o crescimento de ações com o objetivo de consolidar a atuação, com responsabilidade social, dos acadêmicos em comunidades vulneráveis. Por conseguinte, o artigo tem como objetivo relatar a experiência na pandemia de COVID-19 das três disciplinas extensionistas, integrantes do Ateliê Itinerante, intituladas Ateliê de Urbanismo e Paisagismo, Planejamento Ambiental e Projeto Comunitário. Nelas as temáticas desenvolvidas buscaram aproximar as comunidades com a Arquitetura e Urbanismo, almejando também impactar a formação de futuros cidadãos e sua qualidade de vida, por meio da elaboração de projetos nas três escalas, urbanística, paisagística e arquitetônica. A partir dos resultados dos trabalhos e ações desenvolvidas pelos acadêmicos nos territórios foi possível realizar a análise dos impactos da disciplina e seus possíveis desdobramentos na prática durante o isolamento social. Afinal, a interação entre a academia e as comunidades vulneráveis deve estar fundamentada no equilíbrio do conhecimento e aprendizado, superando a visão unilateral e permitindo a troca de experiências. Provocando a transformação das ideias e da superação dos preconceitos recíprocos, pois são mais que projetos e ações, são experiências a fim de viabilizar a interação entre sonho e realidade.

Palavras-chave: Extensão universitária, ensino de arquitetura, projeto urbanístico e paisagístico, planejamento ambiental, arquitetura de interiores.

\section{ABSTRACT}

University extension programs brought new questions and possibilities to university education, encouraging the discussion about how these practices could be theoretically and methodologically inserted in Architecture and Urban Planning schools. Through these programs, we can see the growth of actions which aim to consolidate academic acting in vulnerable communities with social responsibility. Therefore, the article aims to report the experience of three extensionists disciplines, that are part of the Itinerant Studio, due to the covid 19 pandemic. These disciplines are Landscape Urbanism Studio, Environmental Planning and Community Project. The themes developed seek to allow the approach between communities and architecture, impacting

1 Disciplinas extensionistas.

2 Arquiteta e Urbanista. Doutora em Arquitetura. Docente do Curso de Arquitetura e Urbanismo - Universidade Franciscana. E-mail: anelis@ufn.edu.br

3 Arquiteta e Urbanista. Mestre em Planejamento Urbano e Regional. Docente do Curso de Arquitetura e Urbanismo Universidade Franciscana. E-mail: juliana.guma@ufn. edu.br

4 Arquiteta e Urbanista. Mestre em Planejamento Urbano e Regional. Docente do Curso de Arquitetura e Urbanismo Universidade Franciscana. E-mail: liese@ufn. edu.br

5 Arquiteta e Urbanista. Mestre em Patrimônio Cultural. Docente do Curso de Arquitetura e Urbanismo - Universidade Franciscana. E-mail: marina.alcantara@ufn. edu.br 
future citizen's life quality through works in urban planning, landscaping and architectural scale projects. From the student's projects and actions results, it was possible to analyze the discipline's impacts and possible further implications during social isolation. After all, academics and vulnerable communities'interaction must be justified in balance between knowledge and learning, overcoming one sided view and allowing experiences exchanges, inducing the transformation of idea and mutual prejudice, as these are more than projects and actions, but are experiences that make possible dream and reality interaction.

Keywords: University extension programs, Architecture teaching, Urban and landscaping design, Environmental planning, Interiors architecture.

\section{INTRODUÇÃO}

Este artigo tem o objetivo de realizar um relato e a análise dos resultados das disciplinas extensionistas do curso de Arquitetura e Urbanismo da Universidade Franciscana no período de isolamento social imposto pela pandemia da COVID-19. As disciplinas, Ateliê de Urbanismo e Paisagismo, Planejamento Ambiental e Projeto Comunitário, fazem parte do subprojeto Ateliê Itinerante ${ }^{6}$ organizado dentro do Projeto Pedagógico do curso, e visam a aproximação dos acadêmicos com as comunidades vulneráveis da cidade de Santa Maria e região.

A extensão sempre ocorreu no curso a partir da proposição de projetos arquitetônicos, paisagísticos e urbanísticos, assim como de atividades de integração com as comunidades, tornando-se uma prática anterior à Resolução do MEC - CNE/CES 7/20187. Para tanto, estas práticas inicialmente concretizadas no ensino superior como atividades que complementavam o ensino e pesquisa, já possuíam um viés extensionista, quando aproximavam os acadêmicos às demandas e realidades sociais propondo impactar de modo positivo o diálogo, as ações e os pequenos projetos até então realizados.

A partir da Resolução, tal exigência se tornou obrigatória nos currículos dos cursos de graduação por meio das disciplinas denominadas de extensionistas. Esta determinação trouxe novos questionamentos e possibilidades ao ensino superior, fomentando o diálogo sobre como essa prática seria inserida e por fim concretizada no campo da arquitetura.

A Universidade, em seus princípios, possibilitou diversas opções de projetos de extensão, dois deles estão presentes nas disciplinas aqui relatadas: Educação Cultura e Comunicação e Desenvolvimento Regional Sustentável. O primeiro, visa estimular a noção de cidadania, e assim busca a realização de práticas educativas, com expressões artísticas e culturais, em ambientes formais e não formais. O segundo, é um programa que procura o planejamento de iniciativas

\footnotetext{
6 O Ateliê Itinerante configura-se como um subprojeto de ensino-extensão dentro do Projeto de Extensão Integrador denominado Identidade e Inovação Social da Universidade Franciscana.

7 A resolução nº 7 estabelece "As Diretrizes para a Extensão na Educação Superior Brasileira regulamentam as atividades acadêmicas de extensão dos cursos de graduação, na forma de componentes curriculares para os cursos, considerando-os em seus aspectos que se vinculam à formação dos estudantes, conforme previstos nos Planos de Desenvolvimento Institucionais (PDIs), e nos Projetos Políticos Institucionais (PPIs) das entidades educacionais, de acordo com o perfil do egresso, estabelecido nos Projetos Pedagógicos dos Cursos (PPCs) e nos demais documentos normativos próprios" (BRASIL, 2018).
} 
educativas e/ou empreendedoras de caráter econômico ou solidário, sustentáveis, que promovam o crescimento econômico e a melhoria da qualidade de vida.

Nesse sentido, os relatos já demonstram a atuação com elaboração de projetos pelas disciplinas de Ateliê de Urbanismo e Paisagismo e Projeto Comunitário e proposição de materiais didáticos, tanto para a escola como comunidade, também, da disciplina de Planejamento Ambiental. Este contexto poderá ser ampliado nas próximas edições devido o foco no local, pois é importante ressaltar que as disciplinas aqui apresentadas possuem em comum, não apenas o viés comunitário em ambiente vulnerável, como também o mesmo território.

Afinal, esta estratégia potencializou a extensão, dentro dos limites impostos pelas novas circunstâncias da pandemia, e foi capaz de propor várias ações com o objetivo de consolidar a atuação e interação já realizadas na área. Pretende-se, futuramente, que a presencialidade fortaleça estas primeiras experiências e possibilite a efetiva troca de experiências, característica fundamental na construção do vínculo extensionista.

\section{EXTENSÃO NO CURSO DE ARQUITETURA E URBANISMO}

Atualmente, a responsabilidade social tem ampliado o seu alcance dentro dos currículos dos cursos de Arquitetura e Urbanismo, por meio das atividades das disciplinas, que não se contentam em permanecer apenas dentro da sala de aula. Porém foi com a curricularização da extensão que conseguimos sistematizar e assimilar essa prática um tanto intuitiva e, ainda, reforçar o compromisso em formar um profissional capaz de propor, e executar, ações necessárias para o desenvolvimento da sociedade como um todo, não privilegiando apenas o mercado imobiliário.

Antes desta mudança curricular, as disciplinas projetuais, na maioria dos cursos, propunham programas de necessidades voltados para o mercado imobiliário, e até para a especulação imobiliária, não discutindo a cidade real e geralmente desconsiderando-a, "Tudo isso que ensinamos a projetar nas salas de aulas, mas nada disso se constrói na realidade. As cidades empobreceram humanamente, as pessoas empobreceram, de sentido, o ensino empobreceu" (FUÃO, 2015, p. 59).

Dentro desse contexto, o curso de Arquitetura e Urbanismo da Universidade Franciscana desde sua primeira conformação manteve em evidência a responsabilidade social efetiva na sua estrutura, não apenas com os diversos projetos de extensão que atuavam, e atuam ainda hoje, em áreas vulneráveis, como também as disciplinas projetivas e teóricas que já possuíam em suas ementas a aproximação com as comunidades. Isto possibilitou uma fácil adaptação da oficialização deste viés social e agora conseguimos perceber a evolução da extensão universitária em Santa Maria e região.

Portanto, a extensão na Arquitetura e Urbanismo possibilita não apenas a aproximação das comunidades vulneráveis com a universidade, mas também a sensibilização da comunidade acadêmica com o conhecimento a partir de vivências compartilhadas. Vivências baseadas em ações 
educacionais que envolvam outros sujeitos, além do professor e aluno, superando a separação e contribuindo para uma mudança no ensino e novas reflexões na pesquisa.

A seguir, descreveremos as experiências das três disciplinas extensionistas que integram o Ateliê Itinerante e estão alocadas nos programas extensionistas de Educação Cultura e Comunicação e de Desenvolvimento Regional Sustentável. A partir delas apresentaremos sua implantação e as dificuldades superadas no período do isolamento social imposto pela COVID-19.

\section{ATELIÊ DE URBANISMO E PAISAGISMO}

A disciplina de Ateliê de Urbanismo e Paisagismo teve sua primeira edição em 2019 por meio de parceria firmada com a Secretaria Municipal de Educação de Santa Maria, a partir dela foram realizadas atividades na escola Chácara das Flores (2019), localizada no bairro Chácara das Flores. Esta experiência teve continuidade, no ano de 2020, na Escola Diácono João Luiz Pozzobon (2020), localizada na Vila Maringá, porém devido às implicações do isolamento social várias adaptações foram necessárias nas atividades propostas desta edição. Atualmente a disciplina continua no mesmo território, Vila Maringá, realizando uma etapa de sensibilização dos acadêmicos aos anseios e dificuldades lá detectados. Por meio dessa aproximação, dificultada pelo isolamento social, pretende-se desenvolver ações possíveis que venham ser potencializadas no retorno presencial, mantendo assim um vínculo.

A permanência em uma mesma área torna o projeto mais consistente quando além de consolidar as relações sociais ali estabelecidas promove uma maior abrangência no seu alcance, ou seja, permite que um maior número de pessoas tenha acesso aos impactos das ações, sejam moradores, frequentadores ou acadêmicos.

Primeiramente, a disciplina utiliza a rua e o pátio escolar, como temáticas e instrumentos de integração da academia com a comunidade, não apenas contemplando o conteúdo, mas principalmente as estratégias projetuais capazes de fazer o espaço, urbanístico e paisagístico, impactar positivamente a comunidade. A rua de acesso, aqui é vista, como um lugar de convivência, nela os pais esperam seus filhos, falam com os professores, conversam sobre a vida cotidiana, passeiam de bicicleta, caminham em direção ao seu trabalho, à sua casa. O pátio, a rua e a escola fazem parte de um todo, da vida da comunidade. O pátio escolar é um local de aprendizado e merece mais que ser apenas um espaço para a prática de esporte e de brincadeiras na pracinha, nele podemos trocar experiências, complementar a formação e, principalmente, aproximar a comunidade à escola (AZEVEDO; RHEINGANTZ; TÂNGARI, 2011).

A qualidade da cidade está conectada aos espaços livres, espaços que possibilitam a convivência e, portanto, a ideia de liberdade. Espaços que remetem ao encontro e construção de novas sociabilidades, conforme Faria: 
(..) devemos dar um novo papel para as formas espaciais atribuindo-lhes novas funções e criando outros objetos espaciais, os quais já nasçam com uma finalidade social. Fortalecendo a finalidade social dos pátios e dos demais espaços livres urbanos como lugares simbólicos da educação e da vida coletiva e criando as trilhas urbanas de maneira que estruturem novos arranjos educativos na cidade, possivelmente estaremos atendendo a esse desafio (FARIA, 2011, p. 43).

No primeiro semestre de 2020, os acadêmicos tinham como objetivo o desenvolvimento de partidos de projetos urbanísticos e paisagísticos para a rua e pátio da Escola Diácono João Luiz Pozzobon. A etapa de reconhecimento e levantamento do local, foi iniciada pelas professoras (Figura 01), porém com o isolamento social, as atividades de extensão tiveram que ser adaptadas e os acadêmicos, que não puderam visitar o local presencialmente, elaboraram projetos para o acesso à escola e para $\mathrm{o}$ pátio escolar de maneira mais aprofundada.

Figura 01 - Pátio escolar. Levantamento fotográfico realizado na Escola Municipal Fundamental Diácono João Luiz Pozzobon, março de 2020.

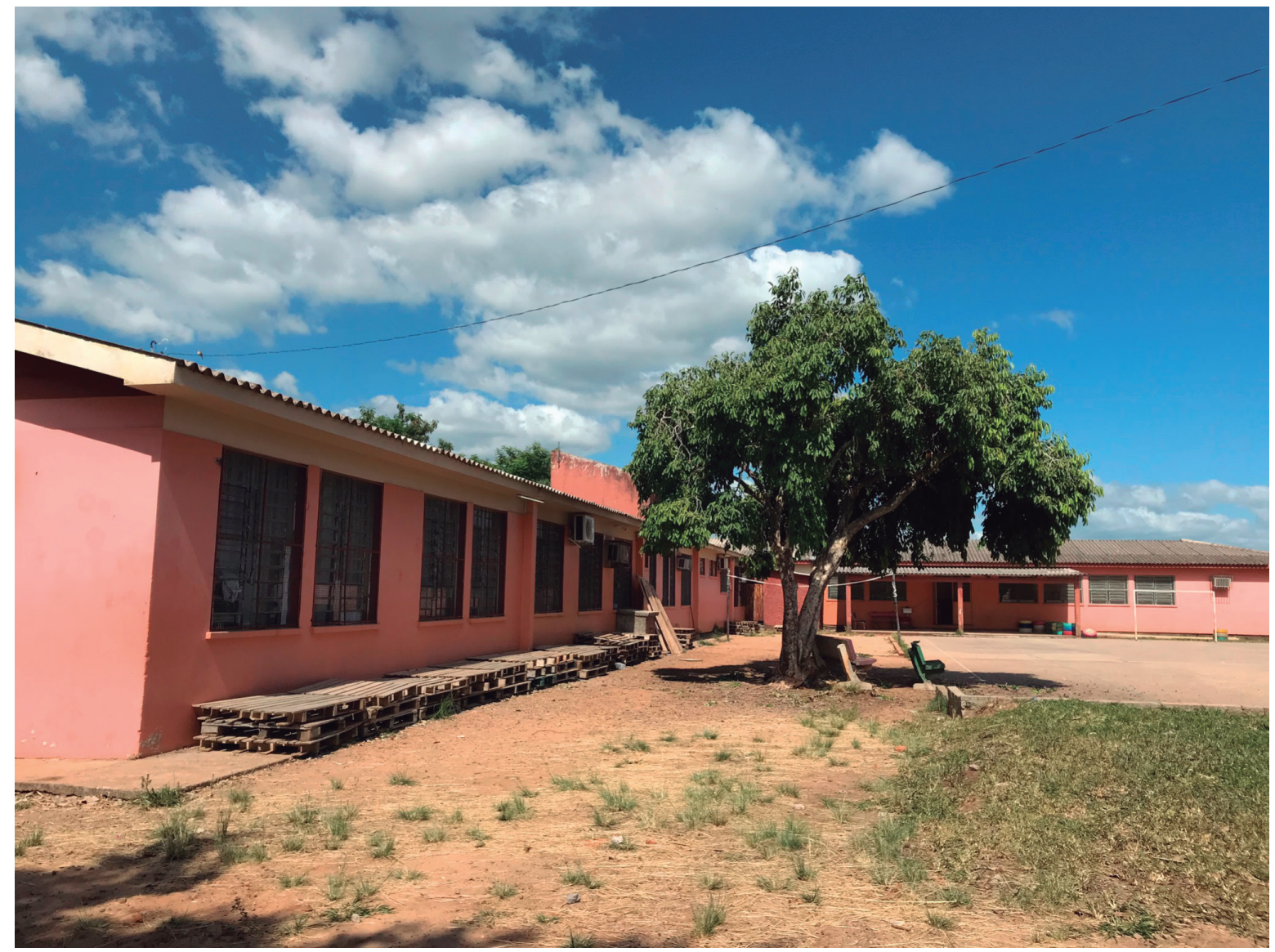

Fonte: Acervo das autoras.

No início do semestre ainda tivemos alguns encontros de forma presencial, neles foram elaborados estudos de casos com a finalidade de preparar as atividades que seriam desenvolvidas na escola. Nestes estudos de caso foram pontuados, principalmente, ações de coletivos com crianças e o universo escolar, assim como o estudo de ruas e pátios com realidades próximas ao local. Um dos coletivos 
estudados foi a Red.OCARA ${ }^{8}$ que permitiu o acesso às pesquisas realizada na américa latina pela arquiteta Irene Quintans sobre a interação das crianças com o espaço público:

A pesquisa da OMO (2016) realizada com 12.000 famílias de dez países, diz que crianças passam menos tempo ao ar livre que presidiários (normas internacionais recomendam como mínimo uma hora de atividade física externa nos presídios). De acordo com o estudo, as crianças raramente passam mais de 30 minutos por dia ao ar livre, e despendem 50\% a mais do seu tempo brincando em frente às telas de computadores e jogos eletrônicos do que do lado de fora de casa (QUINTANS, 2017).

A partir desta premissa, e da vontade de aproximar as crianças e a comunidade escolar do espaço público, iniciamos os debates para os projetos em grupos e as atividades foram divididas por faixa etária com a finalidade de adequar melhor os resultados requeridos para os desenvolvimentos dos projetos da rua e pátio.

Após esta etapa os alunos auxiliados por bibliografia direcionada e material resultante da abordagem teórica inicial elaboraram vinte projetos, em duplas e trios, nos quais foram desenvolvidos além dos desenhos técnicos, textos introdutórios sobre o conceito considerado nas estratégias projetuais. Este material foi selecionado e organizado em um Caderno de Ideias com o objetivo de ser compartilhado com a comunidade escolar e entregue de forma virtual à Secretaria Municipal de Educação de Santa Maria, visto que ao final da disciplina as atividades presenciais ainda não tinham sido retomadas (Figuras 02 e 03).

Figura 02 - Projeto da rua de acesso à Escola Municipal Fundamental Diácono João Luiz Pozzobon, junho de 2020. Grupo de alunos: Francine Bicca e Emmanuelle Albrecht, 2020.

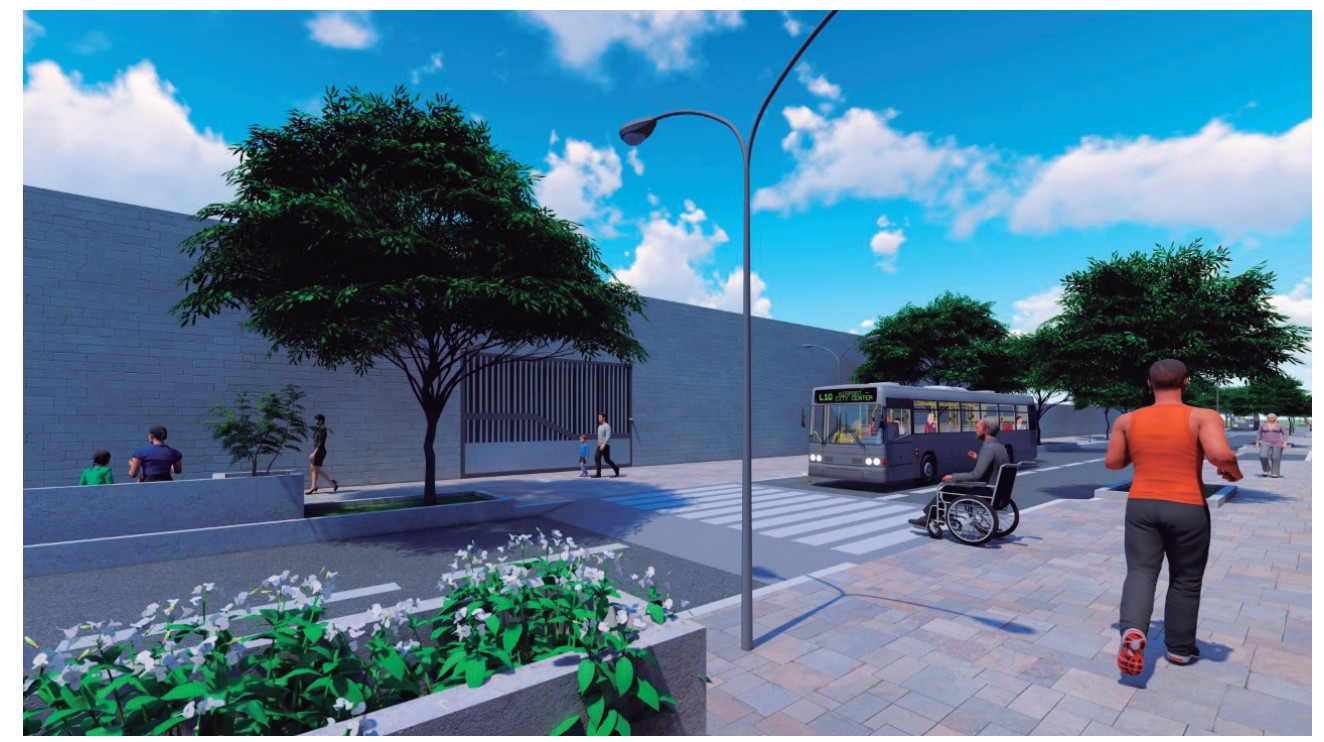

Fonte: Acervo das autoras.

8 Os estudos de caso de ações colaborativas de coletivos como, por exemplo, Red.OCARA, Urb-i, Programa Educatiu Arquiescola e Col.lectiu Punt 6, foram fundamentais para o desenvolvimento das atividades. A RedOCARA se destaca por ser uma rede latino-americana de experiências e projetos sobre cidade, arte, arquitetura e espaço público voltada para as crianças, nela encontramos o compartilhamento de vários grupos coletivos e ações possíveis para os territórios vulneráveis, assim como o "passo-a-passo" para aplicar, replicar, com qualidade e de modo assertivo. 
Figura 03 - Projeto do pátio escolar da Escola Municipal Fundamental Diácono João Luiz Pozzobon, junho de 2020. Grupo de alunos: Ariane Vargas, Bibiana Moreira e Victória Arruda, 2020.

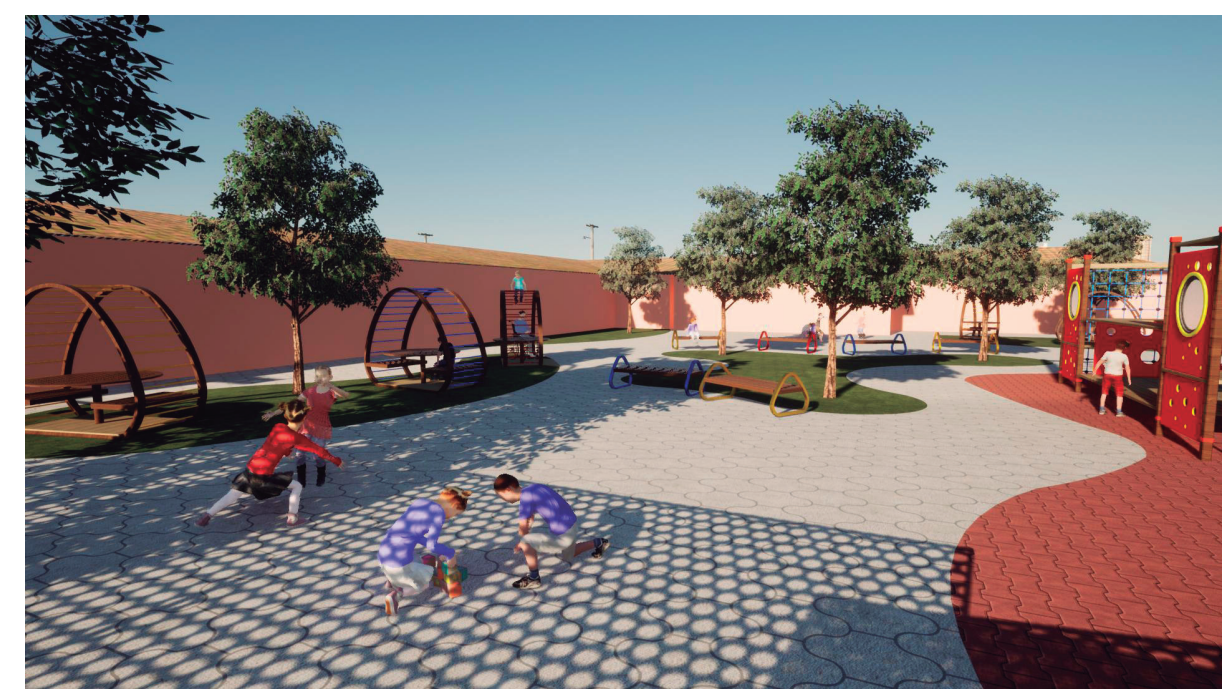

Fonte: Acervo das autoras.

Neste primeiro semestre de 2021, iniciamos novamente a disciplina em formato remoto e desta vez na denominada "Bandeira Preta", com uma maior restrição, não permitindo novamente que os alunos fossem até a escola, porém as professoras realizaram a visita à escola com o intuito de complementar o levantamento, fotográfico e cadastral, realizado em 2020 (Figura 04).

Figura 04 - Pátio escolar. Atualização do levantamento fotográfico e cadastral realizado na Escola Municipal de Ensino Fundamental Diácono João Luiz Pozzobon, abril de 2021.

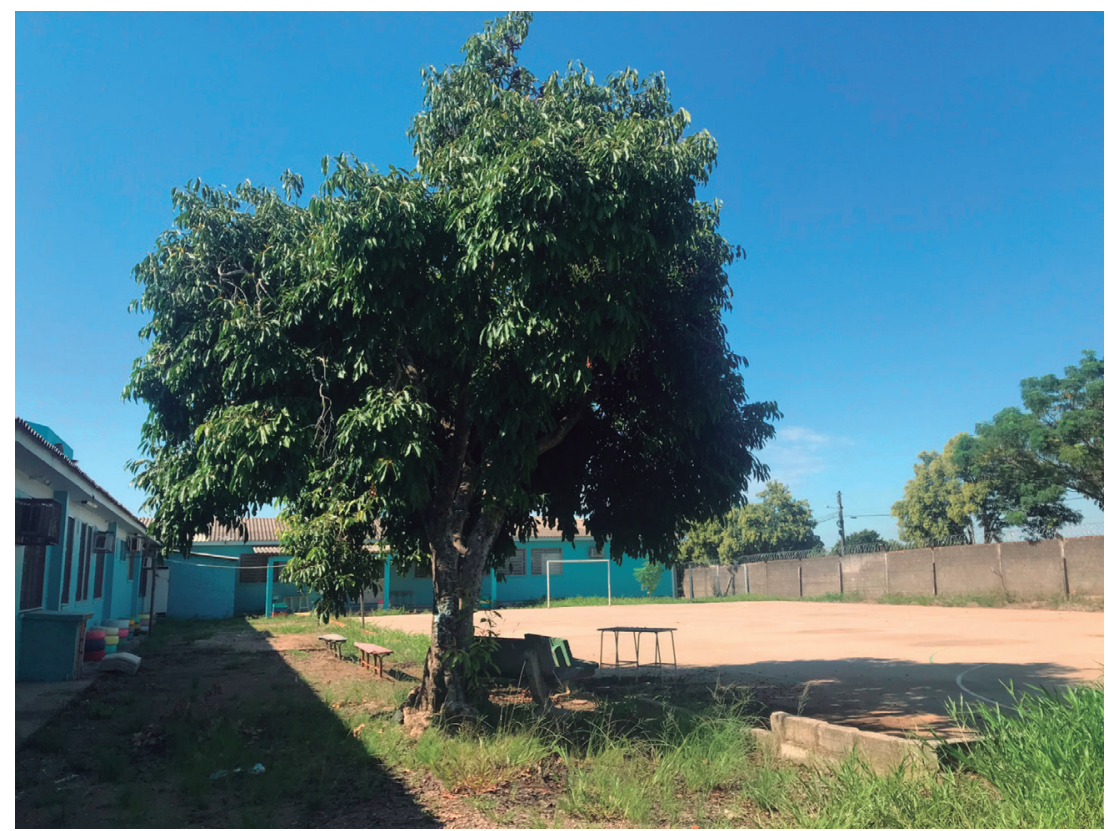

Fonte: Acervo das autoras.

9 O governo do Estado do Rio Grande do Sul elaborou um sistema de bandeiras em 2020, onde foi o pioneiro na sua proposta, propondo medidas de enfrentamento à Covid-19. No período de 27 de fevereiro até 26 de abril de 2021, devido ao esgotamento do sistema de saúde e do aumento significativo de mortos, o Estado entrou em "Bandeira Preta". Vale ressaltar que esse sistema foi extinto e substituído por um modelo estadual mais simplificado denominado "Sistemas 3As" no dia 16 de maio de 2021. A Universidade Franciscana e as escolas do município acataram todas as determinações do governo federal, estadual e municipal, mantendo o ensino remoto e todas as medidas sanitárias requeridas até o momento da elaboração deste artigo. 
A partir do acesso ao material atualizado, assim como dos estudos de caso semelhantes aos desenvolvidos nos outros semestres, os alunos em grupos iniciaram onze novos projetos para a rua e pátio escolar, como o diferencial que nesta edição foi proposta a ampliação da área com a inclusão do acesso e espera, e a possibilidade de inclusão de um terreno baldio contíguo à lateral do pátio.

Também, foi possível por meio da dinâmica de envio de trabalhos para os alunos adotada pela escola, com uma periodicidade quinzenal, a remessa de atividades elaboradas pelos acadêmicos do curso com o objetivo de aproximação e de elaboração de repertório para ser aplicado nos trabalhos a serem desenvolvidos dentro da disciplina. Foram enviados para a escola cinco atividades, sendo escolhidas conforme a faixa etária e que foi sistematizada da seguinte forma: "O que eu quero para a minha escola?" para trinta alunos do $6^{\circ}$ ano, "Como eu quero a minha escola?" vinte e três alunos do $7^{\circ}$ ano e Questionários diferentes sobre o pátio e a rua da escola para vinte alunos do $8^{\circ}$ ano, vinte alunos do $9^{\circ}$ ano e dez alunos do EJA. As atividades de $6^{\circ}$ e $7^{\circ}$ anos convidaram os alunos a desenharem e reconhecerem os espaços escolares por meio de fotografias. Até o momento não retornaram todas as atividades, mas algumas já estão sendo tabuladas.

Dentro do panorama apresentado pela pandemia e de uma situação regida por protocolos, advinda de um maior conhecimento sobre o coronavírus, conseguimos prever a finalização deste semestre de forma mais ativa com a proposição de uma ação para o mês de julho de 2021 que vai além do caderno de ideias, possível no outro cenário. Esta ação permitirá a instalação de uma pequena infraestrutura no pátio para receber os alunos em atividades controladas, principalmente pela demanda de locais externos para retomada gradual. Ela seguirá os seguintes encaminhamentos: Aproximação com a comunidade, seja pelos trabalhos aplicados ou pelo contato firmado com a direção e professores; Parcerias com empresas e pessoas interessadas em auxiliar na aquisição de material para viabilizar o projeto; Mão de obra dos acadêmicos para execução do mesmo e a promoção de um evento, controlado por medidas sanitárias, para verificar as primeiras interações, impressões, da comunidade com o espaço.

\section{PLANEJAMENTO AMBIENTAL}

A disciplina extensionista Planejamento Ambiental, do Curso de Arquitetura e Urbanismo da Universidade Franciscana, teve sua primeira turma ofertada no $1^{\circ}$ semestre de 2020 , e devido a mudanças curriculares recentes, foi formada por cinco alunos. Tem como objetivos auxiliar a compreensão dos processos de ordenamento do espaço e da apropriação dos recursos naturais, através da investigação da crise ambiental do mundo contemporâneo, do conhecimento dos processos de planejamento ambiental e das políticas ambientais aplicáveis à realidade brasileira.

Por fazer parte das disciplinas extensionistas que integram o Ateliê Itinerante, a proposta era realizar ações no mesmo território das demais disciplinas, a fim de fortalecer a relação com a comunidade. 
Após contato inicial com a Secretaria Municipal de Educação de Santa Maria, foi definido que o território para realização da atividade extensionista seria a Escola Municipal de Ensino Fundamental Diácono João Luiz Pozzobon, na Vila Maringá. A proposta era beneficiar toda a comunidade escolar local, que tem aproximadamente quinhentas pessoas, entre alunos, professores e funcionários.

Em meados de março, com o início do isolamento social imposto pela pandemia de COVID19, as aulas foram adaptadas para o modelo remoto. Ao longo do semestre, por meio de aulas expositivas, debates e apresentação de seminários, foram abordados tópicos como impactos ambientais, desenvolvimento sustentável e Educação Ambiental. Como forma de aplicar estes conhecimentos, foi lançado à turma o desafio de propor uma atividade extensionista que gerasse benefícios à comunidade, sem que houvesse a necessidade de contatos diretos. A proposta inicial da disciplina seria interagir diretamente com a comunidade da escola Diácono João Luiz Pozzobon, por meio da realização de entrevistas, levantamentos e ações, o que ficou impossibilitado devido ao isolamento social.

A resposta da turma foi a elaboração de um Manual de Educação Ambiental para escolas municipais da cidade de Santa Maria, que teria como objetivo orientar escolas municipais de Santa Maria em ações no gerenciamento de resíduos sólidos e no consumo consciente de água e de energia. Como não foi possível realizar levantamento de dados diretamente na escola, foi utilizada somente a metodologia exploratória, com realização de pesquisa bibliográfica desenvolvida a partir de material já elaborado sobre o tema proposto e análise de manuais de educação ambiental.

Conforme o artigo $2^{\circ}$ das Diretrizes Curriculares Nacionais para a Educação Ambiental, trata-se de atividade que deve "imprimir ao desenvolvimento individual um caráter social em sua relação com a natureza e com os outros seres humanos, visando potencializar essa atividade humana com a finalidade de torná-la plena de prática social e de ética ambiental” (BRASIL, 2021, p. 2). A partir destas diretrizes, os alunos compreenderam que deveriam abordar no Manual de Educação Ambiental, com uma linguagem simples e acessível, aspectos referentes ao meio ambiente e a crise ambiental que vivenciamos, dando destaque à importância da conservação dos recursos naturais, para então abordar a importância da educação ambiental e o papel fundamental da escola como espaço educador sustentável.

De acordo com Dias (2004), a apresentação de temas ambientais na educação deve enfatizar uma perspectiva geral, sendo importante que sejam desenvolvidas atividades com os estudantes de forma a estimulá-los, tendo em vista que crianças são bastante curiosas. Conforme o autor, a apresentação de temas pertinentes leva à conscientização da criança, que passa a disseminar o novo conhecimento, principalmente para seus familiares" (DIAS, 2004, s/p). No manual foram propostas atividades lúdicas utilizando materiais recicláveis, que os estudantes podem desenvolver em sala de aula com a orientação de professores (Figura 05). 
Figura 05 - Atividades lúdicas propostas no Manual de Educação Ambiental.
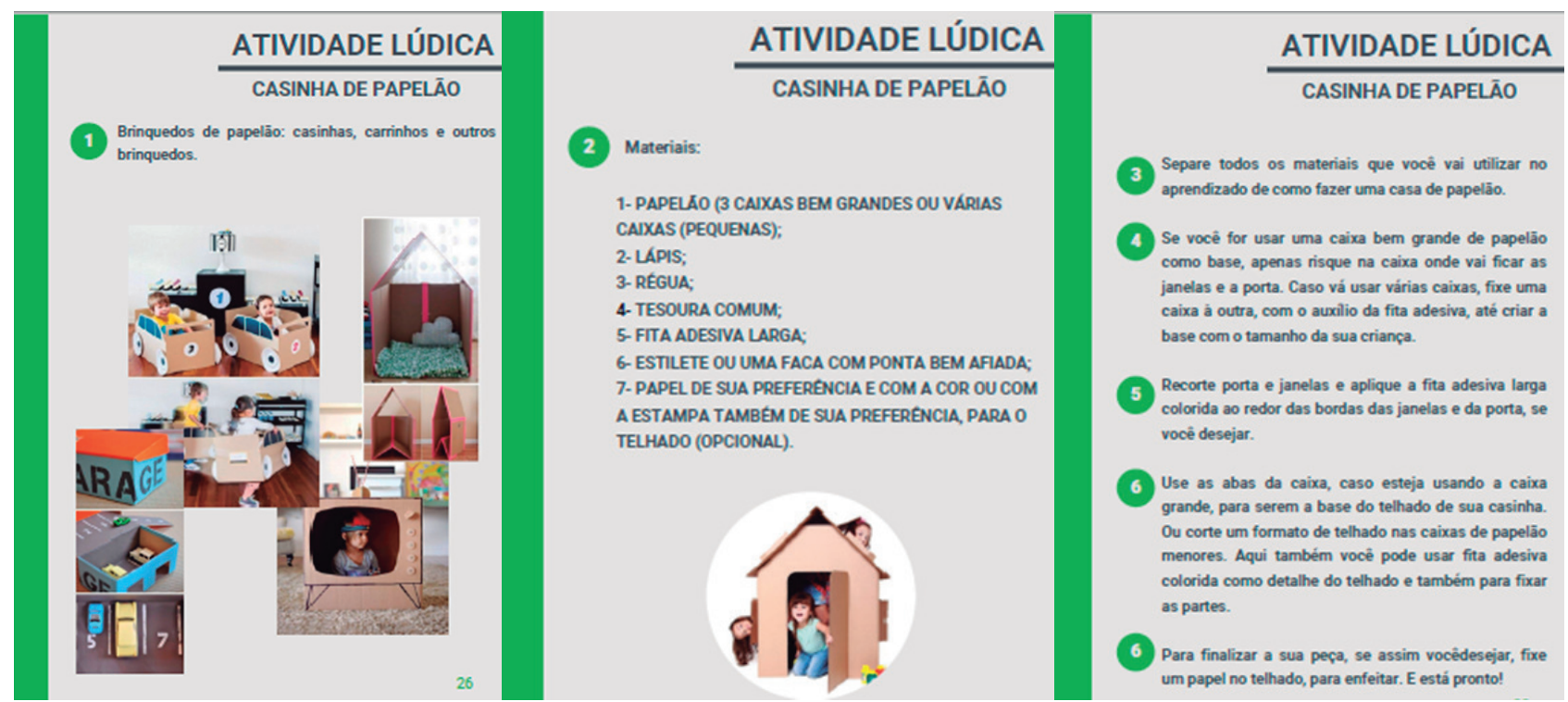

Fonte: Acervo das autoras

Para cada classe de material reciclável, foi proposta uma atividade lúdica (Figura 06).

Figura 06 - Proposta de atividades lúdicas com plástico, vidro e metal reciclados apresentados no Manual de Educação Ambiental.
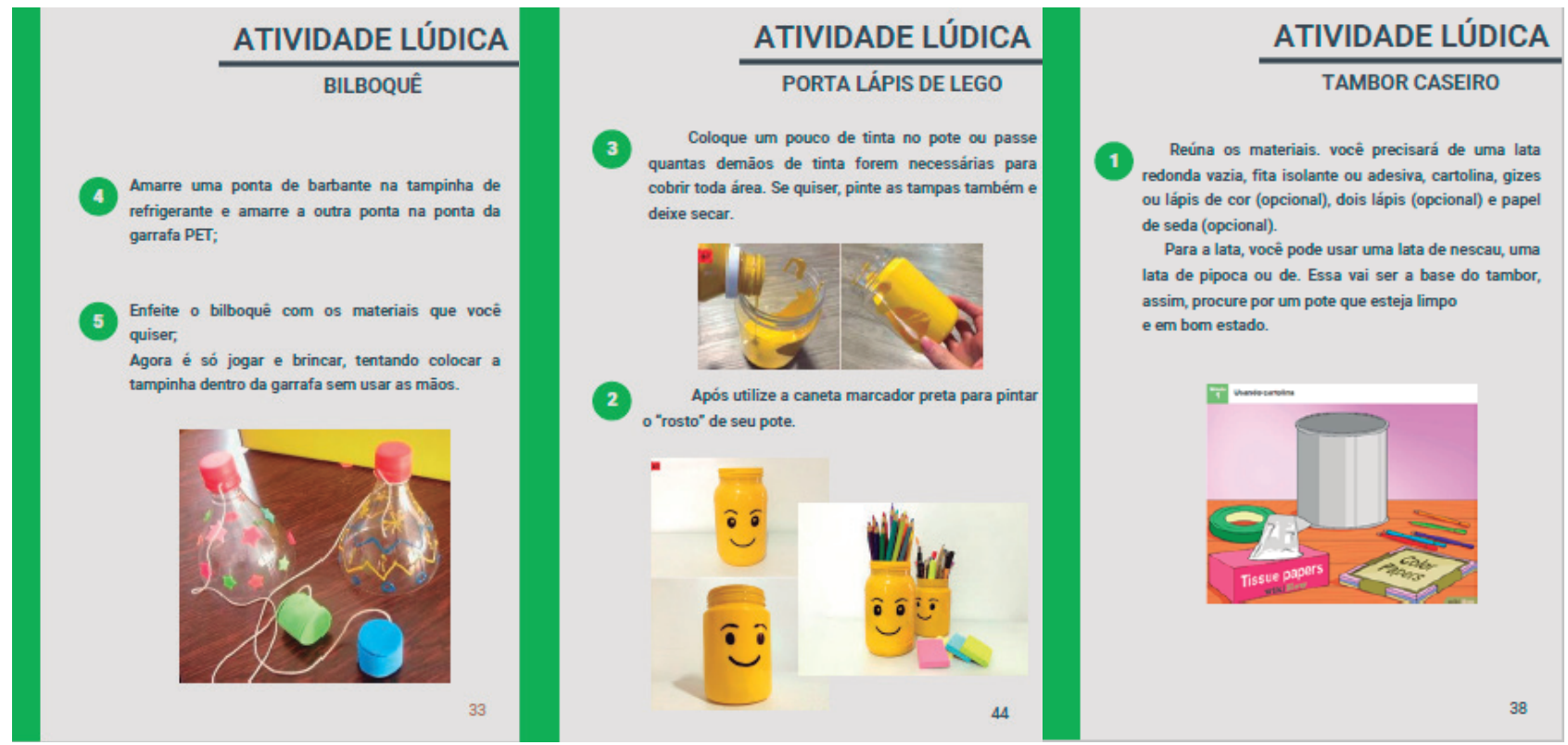

Fonte: Acervo das autoras

Como resultado da atividade extensionista, por meio das informações e atividades lúdicas propostas no manual, pretende-se sensibilizar a comunidade escolar em relação às questões de preservação ambiental e conservação de recursos naturais Segundo Demajorovic (2001), " a ideia de responsabilidade socioambiental depende em grande parte da construção de um novo processo de 
formação da sociedade como um todo, que contemple a redução de riscos ao meio ambiente".

A edição 2021 da disciplina Planejamento Ambiental pretende manter suas ações no mesmo território, desta vez ampliando a área para além dos muros da escola, propondo ações de conscientização ambiental em espaços públicos da comunidade da Vila Maringá e arredores, como praças e espaços da associação comunitária.

\section{PROJETO COMUNITÁRIO}

Projeto Comunitário é uma disciplina obrigatória compartilhada entre os Cursos de Arquitetura e Urbanismo e Design da UFN. O escopo da disciplina explora a formação técnica em projeto de interiores, fomentando nos alunos um olhar global e crítico das habilitações profissionais de ambas as formações e instigando a troca multidisciplinar entre elas.

A primeira edição do Projeto Comunitário ocorreu no segundo semestre de 2019, atuando junto à comunidade da Escola Básica Estadual Cícero Barreto, localizada no Bairro Nossa Senhora do Rosário, na região central de Santa Maria. A escola foi definida como público-alvo da disciplina por tratar-se de uma instituição pública, cuja localização física próxima da UFN viabilizou a análise prévia de possíveis demandas que a escola poderia apresentar.

A fim de fortalecer o subprojeto de Ateliê Itinerante indicado no Projeto Pedagógico do Curso de Arquitetura e Urbanismo, no segundo semestre de 2020, a disciplina repensou sua prática e local de atuação aproximando-se do território de trabalho de outras disciplinas extensionistas, como o Ateliê de Urbanismo e Paisagismo e Planejamento Ambiental. Nesse sentido, desloca seu olhar para a unidade habitacional e qualidade da moradia de famílias beneficiadas pelo Programa Habitacional Minha Casa, Minha Vida (MCMV), em áreas próximas da Escola Diácono João Luiz Pozzobon, na região Centro-Leste da cidade.

Trazer a discussão da qualidade da moradia para a disciplina explora, em um primeiro momento, o conceito da habitação trabalhado nas formações do Arquiteto e Urbanista e do Designer. Entende-se que a unidade habitacional é item necessário para qualquer ser humano, independentemente de sua classe social.

Para Valença (2003), a habitação é mais do que um local de abrigo e segurança, trata-se de espaço ocupado no cotidiano, o local da privacidade, onde as necessidades mais básicas dos indivíduos são atendidas. A disciplina ampara-se no reconhecimento de que a habitação é considerada fundamental para a vivência e convivência humana, aspecto esse que Valença usa para justificar o desejo de todos possuírem uma moradia digna. Santa Maria possui três conjuntos habitacionais de unidades unifamiliares contemplados pelo MCMV Faixa 1, ou seja, acessível à famílias com renda mensal de até R\$1800,00 (BRASIL, 2020).

Diferente das outras disciplinas extensionistas, já relatadas, o Projeto Comunitário é ofertado no segundo semestre do ano letivo, de modo que ao iniciar os trabalhos de 2020, já se viviam as restrições 
impostas pela pandemia de Covid-19. Nesse cenário, a disciplina foi toda organizada para ocorrer de modo remoto, garantindo a segurança e distanciamento social de alunos e comunidade beneficiada.

De modo geral a disciplina se organiza em três momentos: no primeiro momento desenvolvem-se atividades de aproximação temática, contexto de público a ser atendido e reconhecimento do local de trabalho; em um segundo momento aprofunda-se a formação técnica em projeto de interiores, quando os alunos apresentam as propostas de projeto em nível de anteprojeto com algumas definições de detalhamentos e orçamento; e, finalmente, no terceiro momento investe-se em adequar a comunicação técnica das propostas para uma linguagem acessível a um público leigo.

A partir dessa estrutura, entende-se que o processo de desenvolvimento da disciplina prioriza aspectos da formação humana nos acadêmicos, explorando o reconhecimento de mundo e responsabilidade social do Arquiteto e Urbanista e do Designer no primeiro momento de trabalho. No segundo momento destaca a capacitação técnica em projeto de interiores, exigindo a comunicação gráfica de acordo com a linguagem específica de cada profissão. Finalmente, na terceira e última etapa, busca equilibrar o que foi apreendido dos dois aspectos (humano e técnico) a fim de comunicar as propostas de forma sensível ao público-alvo, com uma linguagem de fácil entendimento e adequada tecnicamente.

A proposta de trabalho sugerida aos alunos em 2020 foi o desenvolvimento de projetos de interiores para unidades habitacionais do Conjunto Residencial Zilda Arns e do Conjunto Residencial Dom Ivo Lorscheiter. Uma vez que o contato direto com a comunidade ficou comprometido, o corpo técnico da Secretaria de Habitação e Regularização Fundiária de Santa Maria juntou-se à disciplina a fim de fornecer dados e contribuir com a contextualização da realidade da população a ser atendida.

Uma vez que a visitação nas residências para a realização de levantamentos e contato com as famílias não se mostrava como a melhor medida a ser realizada naquele momento, optou-se por trabalhar com o material gráfico disponibilizado pela Prefeitura Municipal.

Tomando como referência o Sistema Nacional de Cadastro Habitacional (SNCH) ${ }^{10}$ gerido pelo município, construíram-se quatro perfis familiares para os acadêmicos trabalharem em propostas, são estes: (1) Família com 4 pessoas: Casal com dois filhos em idade escolar, sendo um deles cadeirante; (2) Família com 5 pessoas: Casal com dois filhos em idade escolar e um idoso; (3) Família com 5 pessoas: Casal com dois filhos em idade escolar e um bebê; (4) Família com 6 pessoas: Mãe solo com 5 filhos (de 3 a 16 anos).

De posse do projeto arquitetônico, hidráulico e elétrico das residências, os dezesseis grupos de trabalho, organizados em duas turmas, desenvolveram propostas de interiores para a cozinha, estar/ jantar, banheiro e dois dormitórios das residências a fim de atender ao perfil familiar escolhido e a realidade socioeconômica imposta.

$10 \mathrm{O}$ SNCH é a ferramenta utilizada em Municípios e Estados para receber o cadastro e realizar o processo de enquadramento e seleção de famílias que pretendem participar do MCMV. Além de atender os critérios de renda familiar, os candidatos são selecionados a partir de três critérios estabelecidos pelo Governo Federal (residentes em áreas de risco ou insalubres ou que tenham sido desabrigadas; com mulheres responsáveis pela unidade familiar; de que façam parte pessoa(s) com deficiência) e três do Governo Municipal. (BRASIL, 2020). 
Amparados em bibliografia específica, a etapa propositiva fomenta inúmeras reflexões sobre as diferentes condições de moradia que uma população pode enfrentar em uma mesma comunidade. Ressalta-se que causou algum espanto entre os acadêmicos que a unidade habitacional oferecida às famílias é a mesma, independentemente do número de ocupantes ou especificidades de seus moradores, como a presença de mais idosos ou número de crianças.

Durante o semestre, viabilizou-se uma visita técnica ao Conjunto Residencial Dom Ivo Lorscheiter, que guiada pelo líder comunitário, contribuiu para aproximar os acadêmicos do contexto da população que seria alvo dos projetos (Figura 07). A atividade, realizada fora do horário de aula, assumiu caráter opcional aos alunos que se sentissem à vontade e disponíveis para deslocamento, de modo que mobilizou seis acadêmicos.

Figura 07 - Visita técnica realizada ao Conjunto Residencial Dom Ivo Lorscheiter, outubro de 2020.

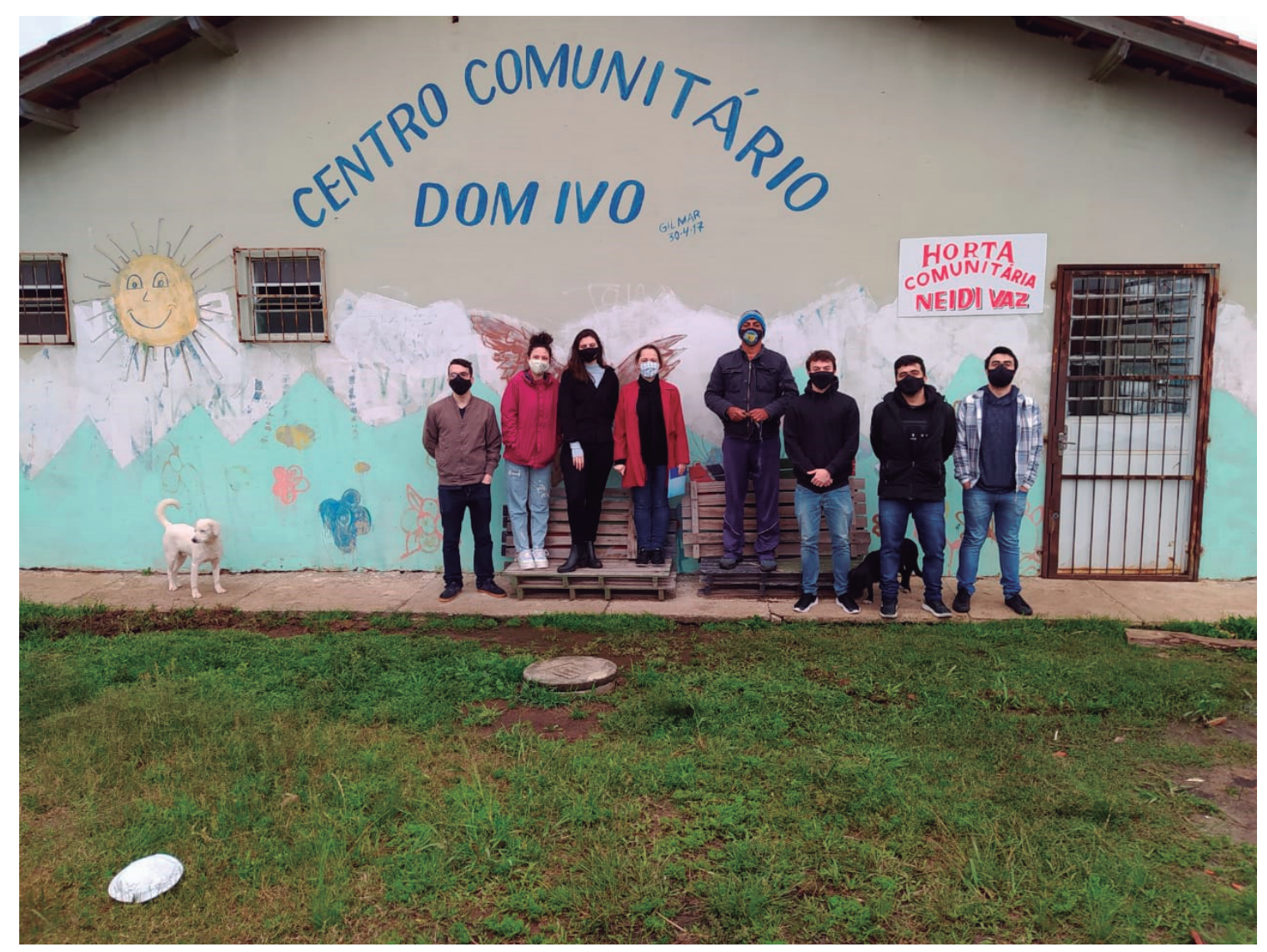

Fonte: Acervo das autoras.

No total foram desenvolvidas dezessete propostas de projeto de interiores, apresentadas tecnicamente em plantas baixas, vistas e elevações internas, imagens e esquemas que explicassem o conceito adotado e a materialidade pensada. Junto do material gráfico, somavam-se tabelas de orçamento de iluminação, revestimentos e mobiliário proposto. Destaca-se que a condição orçamentária é uma imposição na disciplina, de modo que os projetos devem levar esse aspecto em consideração na tomada de decisões. 
Especificamente a respeito dos projetos de mobiliário, a disciplina exercita a busca por móveis disponíveis em lojas de departamento populares ou, em casos específicos, a proposta de móveis do tipo "faça você mesmo" (Figura 08). Essa condição exige dos acadêmicos aprofundamento do conhecimento no que se refere à acabamentos e durabilidade, além de explorar o aspecto criativo e inovador no uso de móveis existentes.

Figura 08 - Proposta de Projeto para Perfil 2, novembro de 2020. Grupo de alunos: Alícia Rodrigues, Carolina Tessele, Lucas Salim e Luiza Cantarelli.

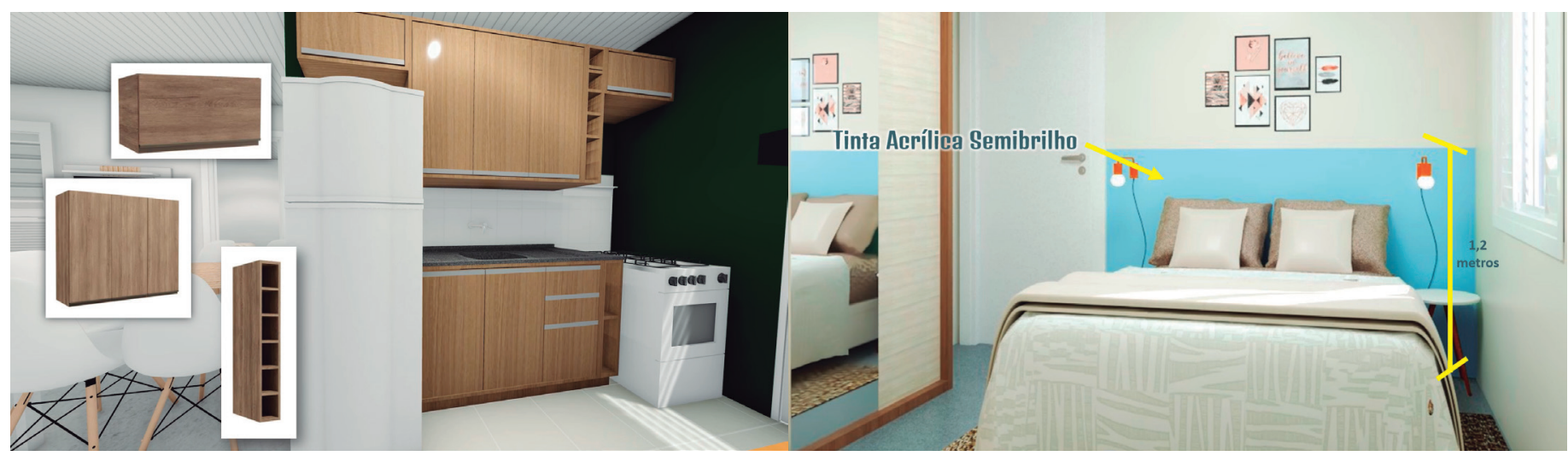

Fonte: Acervo das autoras.

No caso da edição de 2020, a comunicação final de cada projeto foi adaptada para uma produção audiovisual, onde os grupos organizaram uma série de pequenos vídeos em que explicavam as propostas e os condicionantes de projeto considerados. A ideia era de que a comunicação ficasse aberta em redes sociais a fim de orientar e sugerir melhorias em unidades habitacionais do MCMV em qualquer território. Para tanto, criou-se um canal da disciplina em uma plataforma de vídeos onde foram disponibilizados oito projetos.

Os vídeos produzidos foram, ainda, disponibilizados para a comunidade dos Conjuntos Habitacionais Zilda Arns e Dom Ivo Lorscheiter de modo digital via contato com o líder comunitário e para a Prefeitura Municipal de Santa Maria através de contatos com o corpo técnico da Secretaria de Habitação e Regularização Fundiária.

Para 2021, as expectativas da disciplina são da manutenção da temática e do território, aprofundando-se em soluções que respondam de forma mais direta a realidade da comunidade atendida pelo MCMV Faixa 1 em Santa Maria e, se as condições impostas pela pandemia de Covid-19 permitirem, viabilizar o contato direto entre famílias residentes nos conjuntos habitacionais já citados com o grupo de acadêmicos que irão compor a disciplina. A fim de qualificar a interação com a comunidade, a disciplina ainda deve se aproximar da Escola Diácono João Luiz Pozzobon como meio de comunicação com o público, mantendo o vínculo estabelecido nas disciplinas de Ateliê de Urbanismo e Paisagismo e Planejamento Ambiental. 


\section{RESULTADOS E EXPECTATIVAS}

A preocupação com a educação integral do aluno, auxiliando na formação de um arquiteto e urbanista ciente da realidade em que vive e do seu papel enquanto cidadão, sempre permeou os objetivos do Curso de Arquitetura e Urbanismo da Universidade Franciscana. Até 2018, a extensão dentro das disciplinas acontecia de forma não oficial junto aos processos de ensino e pesquisa. A formalização dessas atividades e a criação de disciplinas extensionistas se viabilizou a partir da exigência de sua curricularização proposta pela Resolução do Ministério da Educação (CNE/CES 7/2018).

Nesse sentido, os esforços dentro do curso foram de potencializar os processos de ensino e aprendizagem, vivenciados nas comunidades a partir de demandas sociais com impacto no cotidiano dos atores envolvidos. Buscando, ainda, na adequação da matriz curricular inserir disciplinas que trabalhassem a extensão em diferentes temáticas necessárias à formação do arquiteto e urbanista: arquitetura e patrimônio, paisagismo e urbanismo, planejamento ambiental e arquitetura de interiores. A disciplina que desenvolve a questão patrimonial, Ateliê de Projetos Integrados III, não está relatada neste artigo pois possui especificidades que justificam um relato individualizado.

Apesar do pouco tempo de implementação das disciplinas extensionistas aqui relatadas, as edições já possibilitaram diferentes aprendizados e resultados considerados significativos no que se refere às práticas docentes e à relação universidade e comunidade. Estes tratam desde a introdução de novas metodologias e formas de avaliação discente quanto da busca por um território em que fosse possível compatibilizar os conhecimentos técnicos competentes à formação profissional e as demandas das comunidades atendidas.

Entre os resultados e aprendizados do primeiro ano de implementação das disciplinas foi possível observar a necessidade de atualização da prática docente e da utilização de novas metodologias para sensibilização do acadêmico frente a esta nova demanda. Ainda, constatou-se uma dificuldade em compatibilizar o tempo da comunidade ao tempo disponível na disciplina. Nesse sentido, entendeu-se que a adequação das expectativas e demandas da comunidade e de cada disciplina se fortaleceria se as ações se fixassem em um território único e ali permanecessem por mais tempo.

Após estas primeiras experiências, as novas edições das disciplinas encontraram um espaço conjunto para atuação no Bairro Diácono João Luiz Pozzobon, no qual se encontram o Conjunto Residencial Dom Ivo Lorscheiter, a Vila Maringá e a Escola Municipal de Ensino Fundamental Diácono João Luiz Pozzobon. Em abril de 2020, com a chegada da Pandemia COVID-19 as construções pedagógicas e comunitárias que estavam sendo desenvolvidas necessitaram de importantes adaptações já relatadas. A necessidade sanitária de isolamento social e a adoção de estratégias remotas para o ensino tornaram a prática extensionista um desafio e um aprendizado ainda maiores.

Considerando as especificidades do período, entre os resultados positivos obtidos podemos citar, além da interação do território que facilitou a comunicação com a comunidade: os produtos 
digitais produzidos que podem ter um alcance maior visto à acessibilidade que a internet proporciona, a sensibilização dos alunos para as realidades extramuros da universidade e a dedicação de todos em buscar soluções que amenizem as dificuldades impostas pela pandemia.

Espera-se que em breve ações presenciais nos territórios sejam novamente possíveis para que a extensão prevista na matriz curricular do Curso de Arquitetura e Urbanismo da Universidade Franciscana, possa seguir oportunizando aos alunos a prática de projetos diante de problemas e demandas efetivas da comunidade.

\section{CONSIDERAÇÕES FINAIS}

A Resolução 7/2018, nos Artigos 10 e 11, indica a necessidade de contínua autoavaliação da extensão a fim de verificar as relações entre ensino, pesquisa e extensão e "a formação do estudante, a qualificação do docente, a relação com a sociedade, a participação dos parceiros e a outras dimensões acadêmicas institucionais" (BRASIL, 2018, s/p). Entende-se que este artigo, que teve como objetivo relatar as disciplinas e as dificuldades específicas do período da pandemia, serve também como um instrumento de autoavaliação das atividades até aqui desenvolvidas, suas contribuições para a comunidade acadêmica e a sociedade, de forma geral.

A partir da atuação das disciplinas de Projeto de Urbanismo e Paisagismo e da disciplina de Planejamento Ambiental, proporcionada pela demanda da Secretaria de Educação e consequentemente com a interação com a Escola Diácono Pozzobon, os acadêmicos do curso de Arquitetura e Urbanismo alcançaram uma maior aproximação com a comunidade da Vila Maringá que propiciará os benefícios de uma atividade contínua e, futuramente, consolidada no território. Assim como, permitirá que a disciplina de Projeto Comunitário venha a contribuir para o fortalecimento das ações conjuntas, reforçando o alcance da extensão na comunidade, pois embora sua atuação tenha ocorrido no mesmo território, os agentes de aproximação com a comunidade foram outros.

As ações até o momento realizadas, não apenas produziram materiais didáticos e projetos, como também tiveram um alcance capaz de munir a escola e comunidade de ideias para ampliarem a qualidade de vida e das suas relações sociais, podendo sim, desenvolver a construção de uma realidade mais cooperativa entre eles e ainda com a universidade.

Portanto, a extensão, no contexto das disciplinas relatadas, possibilitou uma nova vivência que extrapolou os limites internos da universidade e encarou a realidade social da cidade de Santa Maria. Espera-se que tais experiências possibilitem aos futuros arquitetos e urbanistas reconhecer e utilizar ferramentas profissionais que auxiliem na transformação dessa realidade.

Por fim, entende-se que as práticas extensionistas nas disciplinas oportunizam a consolidação do ensino, da pesquisa e da extensão como práticas indissociáveis na construção do conhecimento 
necessário à formação de novos profissionais e um importante passo para o fortalecimento da relação das instituições de ensino superior e os outros setores da sociedade.

\section{REFERÊNCIAS}

AZEVEDO, Giselle Arteiro Nielsen; RHEINGANTZ, Paulo Afonso; TÂNGARI, Vera Regina (Orgs.). O lugar do pátio escolar no sistema de espaços livres. Uso, forma e apropriação. Rio de Janeiro, FAPERJ, 2011.

BRASIL, Ministério da Educação. Resolução nº 2/2012. Diretrizes Curriculares Nacionais para a Educação Ambiental. Disponível em: https://bit.ly/2Xs3J1b. Acesso em: 17 maio 2021.

BRASIL, Ministério da Educação. Resolução nº7, de 18 de dezembro de 2018. Brasília, 2018.

BRASIL, Ministério do Desenvolvimento Regional. Programa Minha Casa, Minha Vida. 06/08/2020. Disponível em: https://bit.ly/3aUtMRQ. Acesso em: 17 maio 2021.

DEMAJOROVIC, Jacques. Sociedade de risco e responsabilidade social: perspectiva para a educação corporativa. São Paulo: Senac, 2001.

DIAS, Genebaldo Freire. Educação Ambiental: princípios e práticas. 9. ed. São Paulo. Gaia, 2004.

FARIA, Ana Beatriz Goulart de. O pátio escolar como ter(ritó)rio (de paisagem) entre escola e cidade. In: AZEVEDO, Giselle Arteiro Nielsen; RHEINGANTZ, Paulo Afonso;

TÂNGARI, Vera Regina (Orgs.). O lugar do pátio escolar no sistema de espaços livres. Uso, forma e apropriação. Rio de Janeiro, FAPERJ, 2011.

FUÃO, Fernando Freitas. Lixivia (i) mundi. Coleção Inscritos no Lixo, v. 3. Porto Alegre: UFRGS, 2015.

QUINTANS, Irene. Novas evidências dos impactos das Ruas do Brincar. 2017. Disponível em: https://bit.ly/3n26uis. Acesso em: 5 mar. 2019.

VALENÇA, Márcio Moraes. Habitação: notas sobre a natureza de uma mercadoria peculiar. Cadernos Metrópole, n. 09, p. 165-171, 2003. Disponível em: https://bit.ly/3G221DS. Acesso em: 15 maio 2021. 